\title{
MECHANORECEPTORS IN HUMAN ANKLE LIGAMENTS
}

\author{
JAMES D. MICHELSON, CHRISTOPHER HUTCHINS
}

From the Johns Hopkins University, Baltimore, USA

Chronic ankle instability after ligamentous injuries has been attributed to loss of proprioception, but there has been no previous study of the mechanoreceptors in human ligaments at this joint.

We have examined the ligaments from five cadaver ankles for mechanoreceptors and classified them into the four types described by Wyke and Freeman in their study of feline ligaments. Type-II receptors, thought to provide the sensation of the beginning of joint motion, and type-III receptors, thought to be activated at the extremes of movement, were the most common.

Our findings provide some neuroanatomical data to validate further research into the use of proprioceptive training after ligamentous injuries about the ankle.

J Bone Joint Surg [Br] 1995;77-B:219-24.

Received 8 April 1994; Accepted 15 July 1994

Functional instability of the ankle after a sprain has been attributed to a proprioceptive deficit resulting from articular denervation (Boulton et al 1983). Freeman and others have postulated that the nerve fibres to mechanoreceptors, which are the specialised nerve endings thought to play a role in proprioception, are torn at the time of an ankle sprain (Freeman, Dean and Hanham 1965; Boulton et al 1983). Consequently, treatment for functional instability has focused on proprioceptive retraining of the ankle with variable degrees of success (Freeman 1965).

Many studies have reported the morphology and electrophysiology of the mechanoreceptors in the feline ankle and knee, and to a less extent in the human knee (O'Connor and Gonzales 1979; Schultz et al 1984; Schutte et al 1987; Zimny 1988), but we could find no account of mechanoreceptors in human ankle ligaments. The identification of these nerve endings would help to provide a histological basis for the supposition that ligamentous deafferentation underlies functional instability of the ankle. We have dem-

J. D. Michelson, MD, Associate Professor of Orthopaedic Surgery

C. Hutchins, MD, Resident in Orthopaedic Surgery

The Johns Hopkins Outpatient Center, 601 Caroline Street, Suite 5212. Baltimore, Maryland 21287, USA.

Correspondence should be sent to Dr J. D. Michelson.

(C)1995 British Editorial Society of Bone and Joint Surgery $0301-620 \mathrm{X} / 95 / 2936 \$ 2.00$ onstrated the presence of such mechanoreceptors and studied their distribution in the lateral and medial ligaments of the human ankle.

\section{MATERIALS AND METHODS}

Five pairs of fresh-frozen human legs were dissected from the knee downwards. One leg from each pair (alternating left and right) was thawed and dissected to expose the ankle ligaments. The deltoid ligament was separated from the adherent tendon sheaths of the tibialis posterior and flexor digitorum longus and divided into its superficial and deep segments before removal. The ligaments were then tagged with sutures to maintain spatial orientation, dissected free of the ankle, and either bisected or trisected into proximal, middle, and distal segments to conform with the dimensions of the embedding moulds.

The fresh tissue was then processed and stained by a modification of the gold-chloride technique of O'Connor and Gonzales (1979). Specimens were placed in three parts lemon juice to one part $88 \%$ formic acid in total darkness at $4^{\circ} \mathrm{C}$ for 15 minutes, and subsequently stained with $1 \%$ gold chloride for 45 minutes, also in the dark at $4^{\circ} \mathrm{C}$. After staining, the ligaments were placed in $25 \%$ formic acid for 4 to 6 hours in darkness, washed three times in $70 \%$ ethanol for 10 minutes each, and placed in glycerol for a minimum of 22 hours. They were then dehydrated in $70 \%$ ethanol and two 30-minute cycles of $95 \%$ ethanol. The tissue was infiltrated with Historesin embedding medium under vacuum for a minimum of 48 hours. The suture tags were removed and the specimens were orientated in the embedding moulds.

The specimens were cut in $5 \mu \mathrm{m}$ sections using a rotary microtome. A slice of tissue was retained every $200 \mu \mathrm{m}$ and examined by a Zeiss microscope. Individual mechanoreceptors were counted and placed into groups based on the classification system into four types devised by Wyke and Freeman for their examination of feline articular mechanoreceptors (Wyke 1972: Table I). Of these four morphological and electrophysiological types, only three were recognised in our study. In addition, several other structures were seen which were thought to be mechanoreceptors, based on staining or structural attribute, but which did not entirely resemble those described by Wyke and Freeman (Figs 1 to 5).

Each slice of tissue was divided into superior, middle and inferior regions for the purpose of scoring. This division and the orientation of the specimens in the mould 


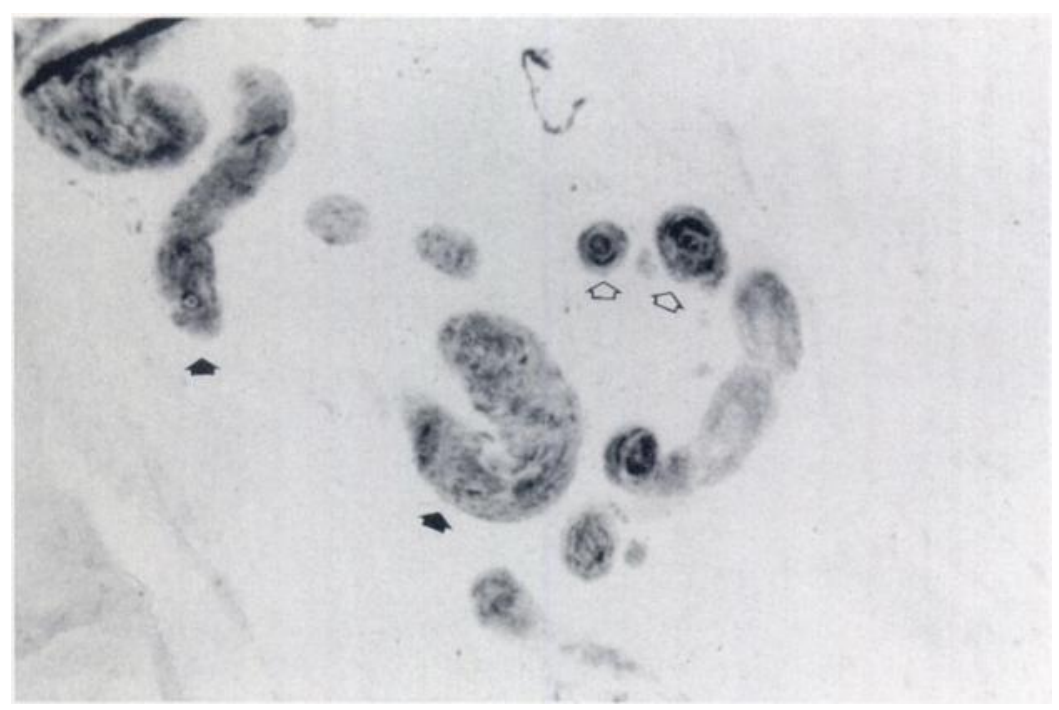

Fig. 1

Photomicrograph of the anterior talofibular ligament showing several mechanoreceptors. The multiple fusiform, thinly encapsulated nerve endings (black arrows) are type-III mechanoreceptors (Wyke 1972). The smaller, oval, thickly encapsulated. lamellar corpuscles (hollow arrows) are type-II mechanoreceptors $(\times 12)$.

Fig. 2

Photomicrograph of a nerve ending in the calcaneofibular ligament. It shows several globular corpuscles (arrows) in a cluster arrangement. which is characteristic of type-I mechanoreceptors. These were the least abundant mechanoreceptors seen in human ankle ligaments $(\times 12)$.

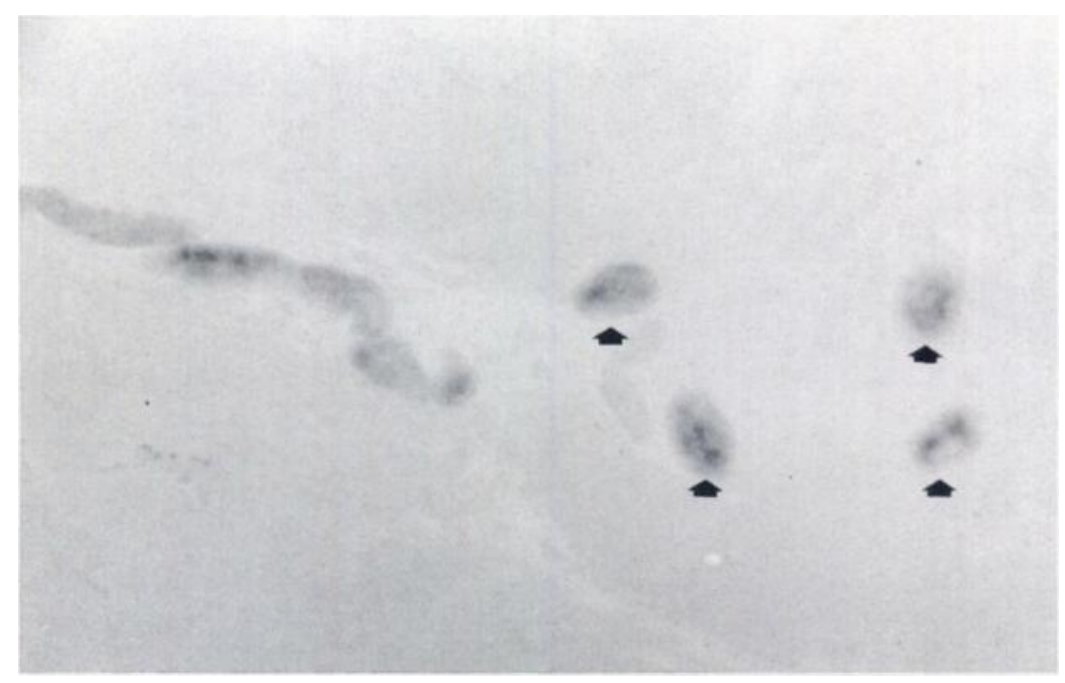

Fig. 3

Photomicrograph of a section of a calcaneofibular ligament. An axon is seen to terminate in at least four type-II mechanoreceptors (arrows) ( $\times 12)$. 


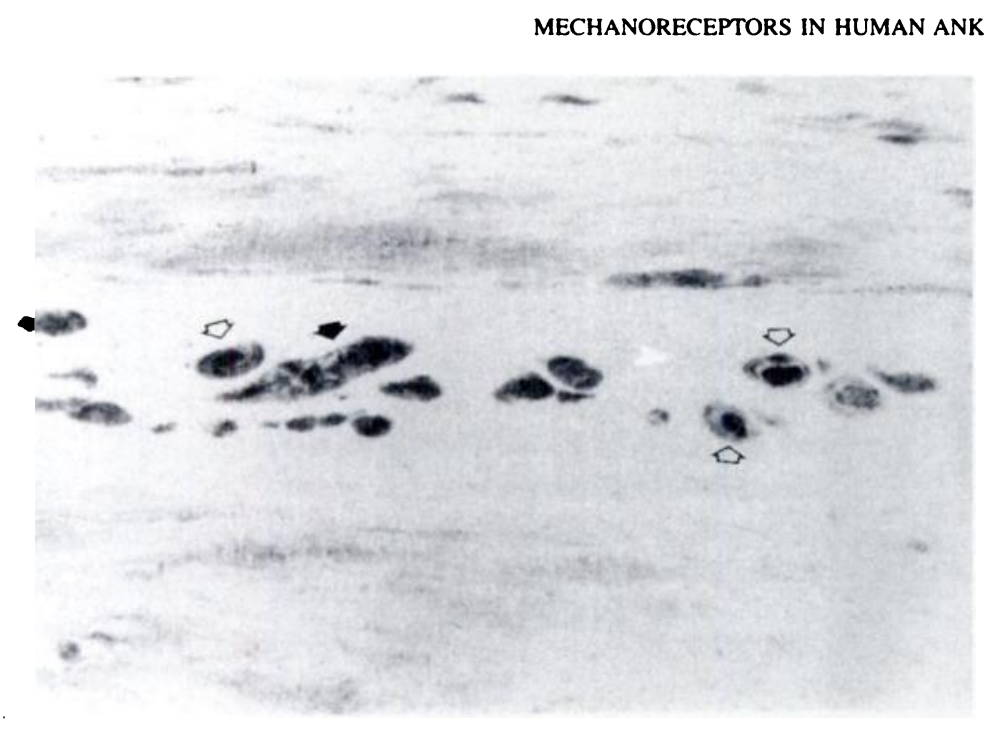

Fig. 4

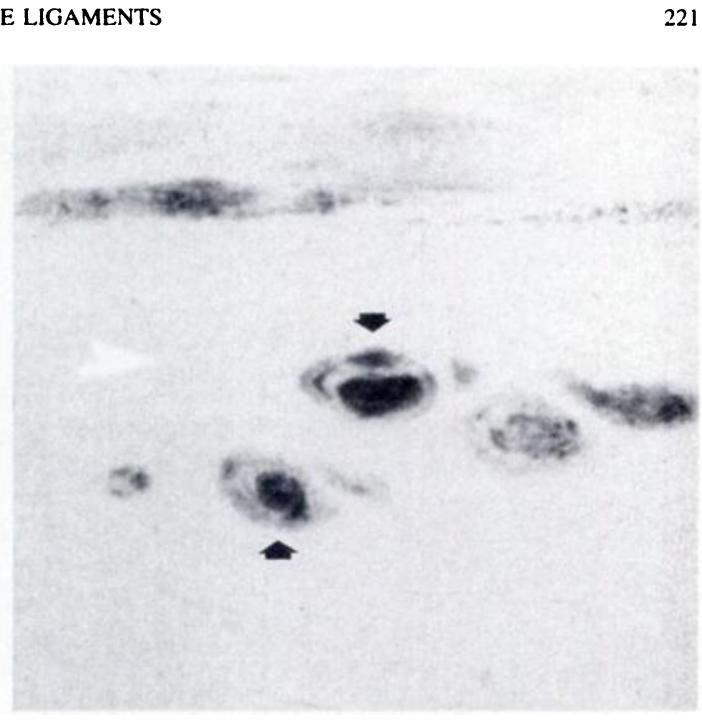

Fig. 5

Figure 4 - Photomicrograph of an anterior talofibular ligament showing one type-III (black arrow) and several type-II receptors (hollow arrows). There are strands of collagen on either side of the mechanoreceptors, and the nerve endings are contained within an intervening septum. This suggests that one nerve may terminate in a variety of different mechanoreceptors $(\times 12)$. Figure $5-$ An enlargement of Figure 4 shows more clearly the lamellar capsular structure of type-II mechanoreceptors (arrows) $(\times 25)$.

Table I. Classification of articular mechanoreceptors abridged from Wyke (1972)

\begin{tabular}{llll}
\hline Type & Morphology & Parent nerve & Physiology \\
\hline I & $\begin{array}{l}\text { Thinly encapsulated } \\
\text { globular corpuscles in } \\
\text { clusters of } 3 \text { to } 6\end{array}$ & $\begin{array}{l}\text { Small, } \\
\text { myelinated }\end{array}$ & $\begin{array}{l}\text { Low threshold, slow adapting } \\
\text { Static and dynamic }\end{array}$ \\
II & $\begin{array}{l}\text { Thickly encapsulated corpuscles } \\
\text { in clusters of } 2 \text { to } 4\end{array}$ & $\begin{array}{l}\text { Medium, } \\
\text { myelinated }\end{array}$ & $\begin{array}{l}\text { Low threshold, rapidly adapting } \\
\text { Dynamic }\end{array}$ \\
III & $\begin{array}{l}\text { Thinly encapsulated } \\
\text { fusiform corpuscles }\end{array}$ & $\begin{array}{l}\text { Large, } \\
\text { myelinated }\end{array}$ & $\begin{array}{l}\text { High threshold, slowly adapting } \\
\text { Dynamic }\end{array}$ \\
IV & $\begin{array}{l}\text { Plexuses and free } \\
\text { nerve endings }\end{array}$ & $\begin{array}{l}\text { Very small. } \\
\text { myelinated }\end{array}$ & $\begin{array}{l}\text { High threshold } \\
\text { Pain receptors }\end{array}$ \\
\hline
\end{tabular}

allowed us to examine the frequency of mechanoreceptors in relation to the bony insertions of the calcaneofibular ligament $(\mathrm{CFL})$ and deltoid ligament and the superficial and deep surfaces of the anterior talofibular ligament (ATFL) and the posterior talofibular ligament (PTFL). Average mechanoreceptor frequencies were determined by counting the total number of each type for each cross-section of ligament. We then compared regions and segments of ligaments using non-parametric analysis of variance.

\section{RESULTS}

Mechanoreceptors were observed in all the examined ligaments and were present throughout the ligament and in periligamentous connective tissue. Within the ligament, the mechanoreceptors tended to be located in connective-tissue septa which penetrated the ligaments (Figs 1 to 5). On the classification of Wyke and Freeman (Wyke 1972), three of their four types of mechanoreceptor were detected in each ligament. Type-I receptors, thinly encapsulated globular corpuscles, were seen in all ligaments, but at a low frequency (Fig. 6). Type-II mechanoreceptors, thickly encap- sulated conical corpuscles thought to have proprioceptive function (Fig. 3), were the most common in all the ankle ligaments. Type-III mechanoreceptors (Fig. 1), appearing as thinly encapsulated fusiform corpuscles, were also seen in relatively high frequency in all ligaments. There was no discernible segregation of mechanoreceptors within the

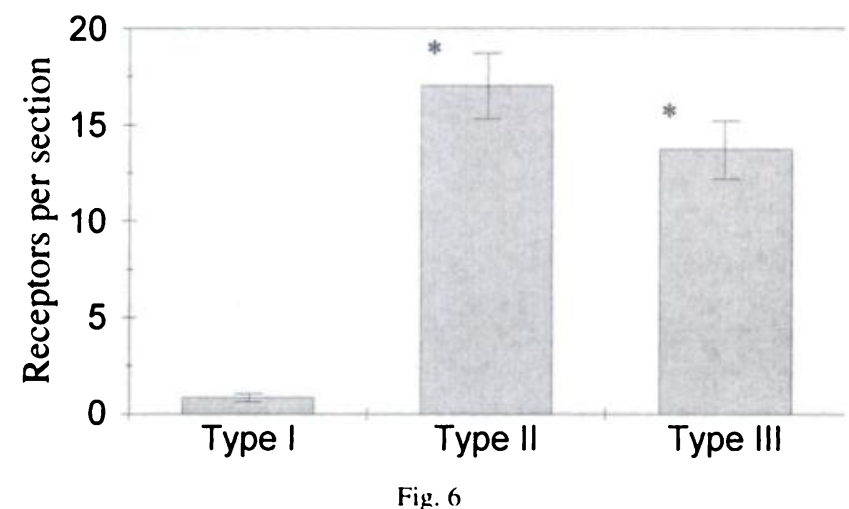

Distribution of three types of mechanoreceptor within human ankle ligaments. The bars represent the mean \pm si) number of receptors seen per cross-section of ligament. There were significantly more type-II and typeIII receptors $(*, p<0.05)$. 


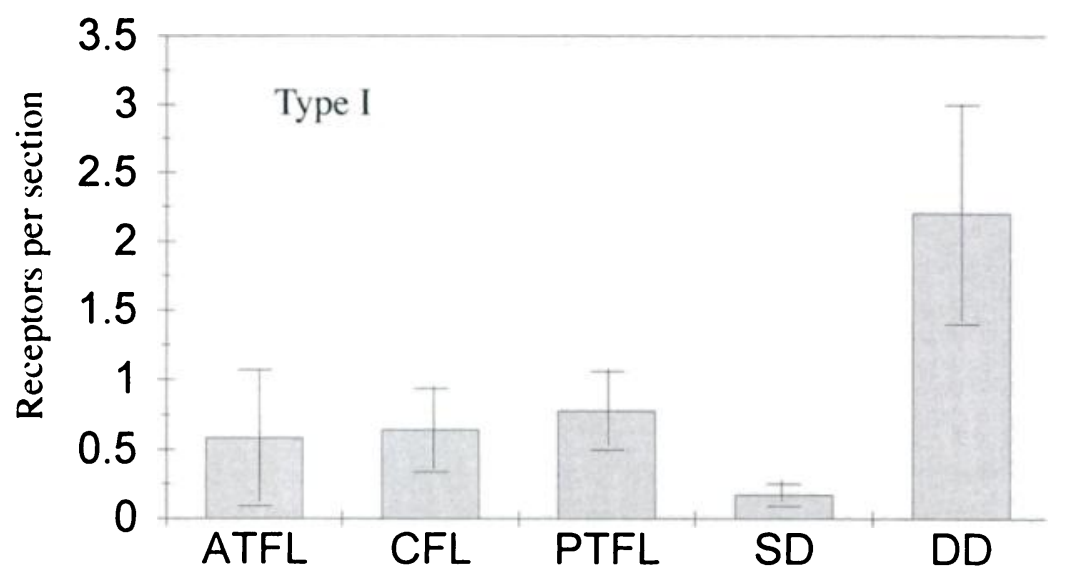

Fig. 7

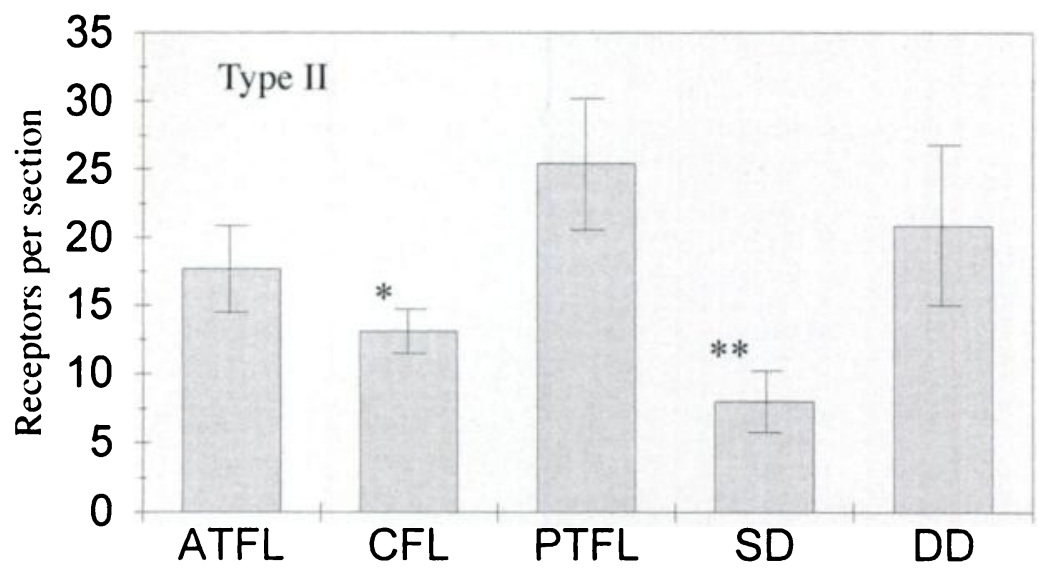

Fig. 8

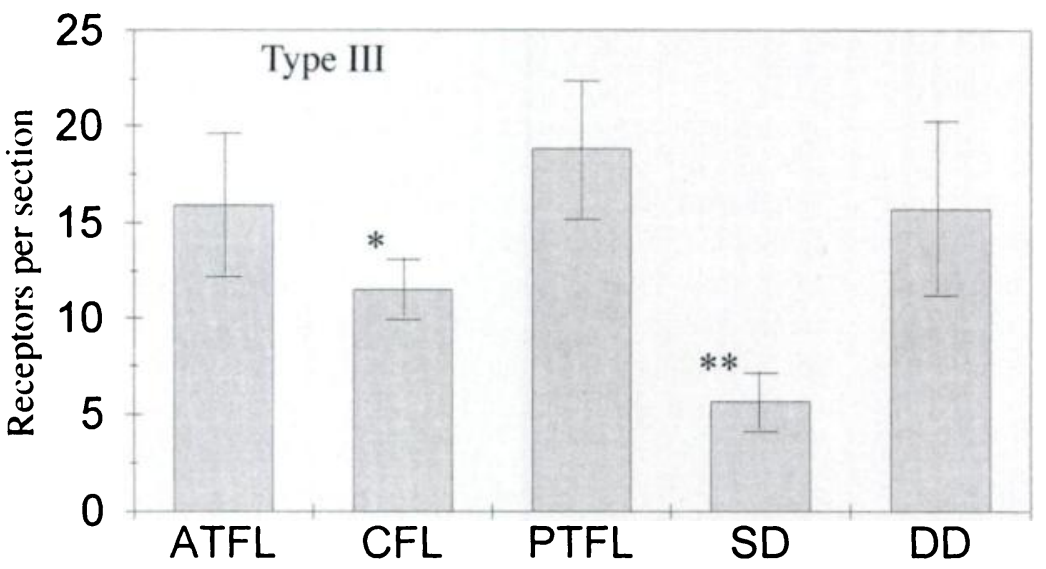

Fig. 9

ligaments; several types were frequently seen in close proximity to one another (Fig. 1). Occasionally, we observed a single nerve axon terminating in multiple mechanoreceptors of one type (Fig. 3). A single nerve fibre could also supply several types of mechanoreceptor (Fig. 4).

Type-I mechanoreceptors were found in small numbers throughout all five ankle ligaments; there were no significant differences between ligaments (Fig. 7). Type-II and type-III mechanoreceptors were seen with significantly higher frequencies than type-I in all ligaments (Fig. 6). The

\begin{abstract}
Anatomical distribution of mechanoreceptors in human ankle ligaments. The bars represent the mean \pm SI) numbers of receptors seen per crosssection. Ligaments: ATFL. anterior talofibular: CFL. calcaneofibular: PTFL. posterior talofibular: SD. superficial deltoid: DD, deep deltoid.

Figure 7 - Type-I mechanoreceptors. None of the differences was significant.

Figure 8 - Type-Il mechanoreceptors. The CFL showed signiticantly fewer receptors $(*, p<0.005)$ than the PTFL. The SD** had significantly fewer receptors than the ATFL $(p<0.04)$, the CFL $(p<0.001)$, and the DD $(p<0.01)$.

Figure 9 - Type-III mechanoreceptors. The CFL had significantly fewer receptors $(* . p<0 .(05)$ than the PTFL. The SD** showed significantly fewer receptors than the ATFL $(p<0.04)$, the CFL $(p<0.001)$, and the DD $(\mathrm{p}<0.01)$.
\end{abstract}




\section{DISCUSSION}

Many investigators have demonstrated articular mechanoreceptors in various joints in animals (Freeman and Wyke 1964, 1967a,b; Wyke 1967; O'Connor and Gonzales 1979; Zimny 1988) as well as in man (Schultz et al 1984; Schutte et al 1987; Zimny 1988; Johansson, Sjölander and Sojka 1991b). In the cat, mouse, and chicken, receptors have been demonstrated both within capsular tissues (Freeman and Wyke 1964, 1967a) and in the substance of ligaments (Freeman and Wyke 1967b; O'Connor and Gonzales 1979; Zimny 1988). In man, mechanoreceptors have been demonstrated in ligaments only within the knee (Schultz et al 1984; Schutte et al 1987; Zimny 1988) and in cartilaginous tissues in the knee and the temporomandibular joint (Zimny 1988). We have shown that mechanoreceptors of the type previously discovered in other joints are also present in the ligaments of the human ankle.

Mechanoreceptors were initially classified by their histological appearance (Table I), and later studies aimed to relate the morphology to their electrophysiology (Wyke 1972; Zimny 1988). Type-I receptors, which we found infrequently in human ankle ligaments, are slowly-adapting receptors with a low threshold. They have continuous firing, even at rest, and it has been postulated that they provide postural sense to the central nervous system. In contrast, type-II receptors are dynamic with rapid adaptation; they too have a low threshold, and are thought to convey a sense of the beginning of joint motion. In the human ankle these were abundant in all ligaments. Interestingly, previous studies (Wyke 1972) have reported that type-I and type-II mechanoreceptors were primarily sited in joint capsules with very few, if any, in ligaments. Type-III receptors are also dynamic-type receptors, but have a high threshold and slow adaptation. They are thought to provide sensation at the extremes of movement and are abundant in human ankle ligaments. Type-IV receptors are free nerve endings in the tissues and are responsible for nociceptive sensation. These nerve endings have been described in feline ankle ligaments (Freeman and Wyke 1967b), but we were unable to demonstrate them in the human ankle.

Figure 6 shows that type-II and type-III mechanoreceptors were significantly more abundant than type-I in human ankle ligaments, in each individual ligament, and in all the ligaments taken together. Since type-I mechanoreceptors probably mediate postural sense it seems that very few receptors are required for the conveyance of static position. The presence of type-II receptors (which sense the initiation of joint movement) in the ligaments implies that the initiation of motion of the human ankle involves stress transmission through the ligaments. Type-III mechanoreceptors were also abundant, and this is consistent with the theory that they are active at the extremes of movement of a joint; they probably act to alert the central nervous system of imminent danger to the joint.

In the feline knee (O'Connor and Gonzales 1979) and ankle (Freeman and Wyke 1967b), the ligament mechanoreceptors were seen primarily on the superficial surfaces of the ligaments. In the human ankle we found that mechanoreceptors were evenly distributed throughout the substance of the ligaments, usually in small fibrous septae running parallel to the ligament fibres. It could be speculated that longitudinal tension on a ligament results in compression of the interstitial septae, and that this would serve to stimulate the mechanoreceptors within. This anatomical arrangement would then serve as a tension-to-compression transduction mechanism.

Transarticular ligaments provide more than simple structural support for the joint. Aside from the proprioception which is provided (Wyke 1972), the available data strongly suggest that the sensory output from ligaments aids in controlling muscle stiffness and co-ordination around a joint, thereby increasing stability (Johansson, Sjölander and Sojka 1991a; Johansson et al 1991b). Mechanoreceptors are thought to have roles in kinesthaesia, muscle tone, and articular reflexes (Freeman and Wyke 1967a; Johansson et al 1991b). The precise mechanisms by which mechanoreceptors accomplish these multiple functions are unknown, but it is generally held that they influence gamma motor neurone output, thereby determining the length of muscle spindle fibres (Freeman and Wyke 1967a; Johansson et al 1991b). Mechanoreceptors thus influence the discharge of $1 \mathrm{~A}$ spindle afferents, which ultimately input on alpha motor neurones. They may therefore modulate alpha-motor-neurone outflow to enhance muscle contractility. It may well be that mechanoreceptor-mediated joint proprioception acts by influencing muscle length or tension or by both these mechanisms. At the extremes of motion, mechanical receptors also elicit protective reflexes to prevent injury to the joint (Zimny 1988).

Damage to ligaments and their associated mechanoreceptors has been shown to result in deficient proprioception after injuries of the knee and the ankle (Freeman et al 1965; Schutte and Happel 1990). Rehabilitation from such injuries must therefore take into account not only the structural abnormality, but also the loss of sensory feedback that results (Johansson et al 1991b). Specific exercises for ankle rehabilitation have been developed to restore lost proprioception after ankle sprains (Freeman 1965), and it has been shown that these give better functional results than rehabilitation without proprioceptive training (Freeman et al 1965).

Our study has provided some neuroanatomical data to validate the use of proprioceptive training after ligamentous injuries about the ankle. It is not yet known whether this type of rehabilitation influences surviving mechanoreceptors in the ligaments, or provides for substitution by mechanoreceptors in the joint capsule or the surrounding muscle-tendon units.

No benefits in any form have been received or will be received from a commercial party related directly or indirectly to the subject of this article. 


\section{REFERENCES}

Boulton AJ, Hardisty CA, Betts RP, et al. Dynamic foot pressure and other studies as diagnostic and management aids in diabetic neuropathy. Diabetes Care 1983:6:26-33.

Freeman MA. Co-ordination exercises in the treatment of functional instability of the foot. Physiotherapy 1965:51:393-5.

Freeman MA, Wyke B. Articular contributions to limb muscle reflexes: an electromyographic study of the influence of ankle-joint mechanoreceptors upon reflex activity in the gastrocnemius muscle of the cat J Physiol (Lond) 1964;171:(Supp)20-1.

Freeman MAR, Dean MRE, Hanham IWF. The etiology and prevention of functional instability of the foot. J Bome Joint Surg $[\mathrm{Br}$ 1965:47-B:678-85.

Freeman MA, Wyke B. Articular reflexes at the ankle joint: an electromyographic study of normal and abnormal influences of ankle-joint mechanoreceptors upon reflex activity in the leg muscles. $\mathrm{Br} J$ Surg 1967a;54:990-1001.

Freeman MAR, Wyke B. The innervation of the knee joint: an anatomical and histological study in the cat. J Anat 1967b:101:505-32.
Johansson H, Sjölander P, Sojka P. A sensory role for the cruciate ligaments. Clin Orthop 1991a:268:161-78.

Johansson H, Sjölander P, Sojka P. Receptors in the knee joint ligaments and their role in the biomechanics of the joint. Crit Rev Biomed Eng 1991b;18:341-68.

O'Connor BL, Gonzales J. Mechanoreceptors of the medial collateral ligament of the cat knee joint. J Anat 1979:129:719-29.

Schultz RA, Miller DC, Kerr CS, Micheli L. Mechanoreceptors in human cruciate ligaments: a histological study. J Bone Joint Surg $(\mathrm{Am})$ 1984:66-A:1072-6.

Schutte MJ, Dabezies EJ, Zimny ML, Happel LT. Neural anatomy of the human anterior cruciate ligament. J Bome Joint Surg $(\mathrm{Am})$ 1987:69-A:243-7.

Schutte MJ, Happel LT. Joint innervation in joint injury. Clin Sports Med 1990:9:511-7.

Wyke B. The neurology of joints. Ann $R$ Coll Surg Engl 1967:41:25-50.

Wyke B. Articular neurology: a review. Physiotherapy 1972:94-9.

Zimmy ML. Mechanoreceptors in articular tissues. Am J Anat $1988 ; 182: 16-32$. 